\title{
工

\section{O debate sobre o lócus e nível da formação de professores para a educação básica no Brasil}

\section{The debate about the locus and the level of formation of teachers for the basic education in Brazil}

\author{
José Júlio César do Nascimento Araújo \\ Instituto Federal do Acre \\ Marcondes de Lima Nicácio \\ Instituto Federal do Acre
}

Recebido em 12 de outubro de 2018

Aprovado em 01 de abril de 2019

Publicado em 10 de abril de 2019

\section{RESUMO}

O artigo tem como objetivo discutir a categoria lócus de formação docente no Brasil e a política atual dos Institutos Federais de Educação, Ciência e Tecnologia como novo lócus de formação de professores. A pesquisa baseia-se em revisão bibliográfica e análise documental sobre o tema. A primeira parte do texto traz um panorama histórico da formação de professores e a segunda parte analisa as categorias lócus e nível de formação em evidência nas políticas a partir dos anos de 1990. Atreladas a complexa reorganização produtiva do país e oriundas das propostas dos organismos internacionais. Nessa perspectiva, erige-se o modelo neoliberal de formação de professores que tem se propalado até a atualidade. Nas considerações finais, são levantadas questões no sentido de problematizar a formação docente ao indicar efeitos como: a instabilidade da profissão, aceitação de múltiplos espaços de formação, a não garantia de uma formação socialmente referenciada e a dificuldade de cumprimento das metas do PNE (2014-2024).

Palavras-chave: Lócus; Nível; Formação docente.

\section{ABSTRACT}

The article has as its main objective to discuss the locus category of teacher training in Brazil and the actual politics of the Federal Institutes of Education, Science and Technology as new locus of teacher training. The research is based on bibliographic revision and documental analysis on the theme. The first part of the text brings a historical panorama on the teacher training and the second part analyses the categories locus and level of training in evidence on the politics from the 1990s trailed 


\section{OTLFH Eutiraţa}

ISSN: 1984-6444 | http://dx.doi.org/10.5902/1984644435164

to the complex productive reorganization of the country and originating from the propositions of the international organs. On that perspective, it builds up a neoliberal pattern of teacher training which has proclaimed to the current days. In the final considerations, questions are raised trying to question the teacher training indicating such effects as: the instability of the profession, the acceptance of multiple training spaces, the no guarantee of a socially referenced formation and the difficulty in fulfilling the goals of the National Plan of Education (PNE, Plano Nacional de Educação) (20142024).

Keywords: locus; level; teacher training.

\section{Introdução}

Em tempos que se centram as discussões sobre lei da mordaça para professores, sobre a necessidade de uma escola sem partido', na reforma previdenciária, no teto para gasto público com educação e saúde, entre tantas outras pautas e, ainda, incita-se a sociedade civil a propalar as máximas da direita conversadora que caracterizam o professor como não educador, discutir a formação, nestes tempos de exceções, torna-se urgente.

Este trabalho que ora se apresenta teve início em 2014, com os estudos de doutoramento em educação, em sua fase exploratória. A partir de ampla leitura sobre a educação profissional e a transformação na Rede de Educação Profissional e Tecnológica, o Materialismo Histórico Dialético e a práxis como docente em IF nos possibilitou as reflexões e a categorização sobre a realidade enfrentada com a finalidade de construir o real por meio da teoria e reconstruir a teoria através da práxis.

Desta feita, nesta fase de pesquisa bibliográfica e documental, se buscou uma discussão contextualizada e histórica da problemática da precarização para "fundamentar teoricamente o objeto de estudo, contribuindo com elementos que subsidiam a análise futura dos dados obtidos, [...] [imprimindo] sobre eles a teoria, a compreensão crítica do significado neles existente" (LIMA; MIOTO, 2007, p.44). A seleção dos textos foi realizada nos repositórios das revistas. Além disso, foram consultados livros de autores que estudam a temática no mundo do trabalho. 


\section{$\sim$ uss

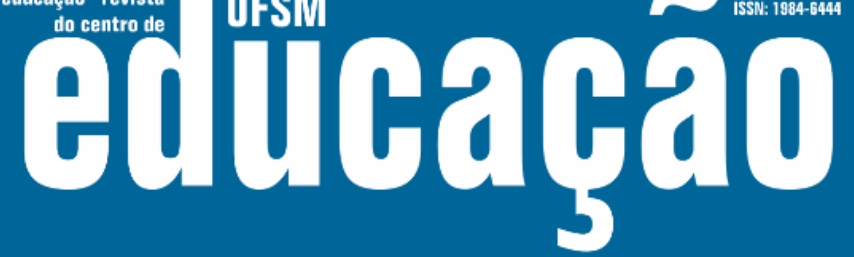

ISSN: 1984-6444 | http://dx.doi.org/10.5902/1984644435164

Após essa fase, os documentos e a literatura foram organizados e analisados utilizando o software para análise de pesquisa qualitativa $N$ Vivo 11 Starter e nos pressupostos da Análise de Conteúdo temático-categorial (GUERRA, 2014). Como apresentamos a seguir:

I. Organização da análise

- Leitura flutuante e analítica;

- Definição das unidades de análise com base nas questões norteadoras da pesquisa;

- Identificação das categorias e subcategorias emergentes;

II. Exploração do material

- Construção das categorias para análise;

- Codificação e categorização dos dados com apoio software para análise de pesquisa qualitativa $N$ Vivo 11 Starter for Windows.

III. Análise dos resultados

- Organização dos quadros de análise com os extratos de discurso correspondentes as categorias;

- Análise do conteúdo;

- Inferências e interpretações;

Construímos esse caminho apoiados no apontamento marxiano que leciona que a investigação deve apoderar-se da matéria, em seus pormenores, analisar suas diferentes formas de desenvolvimento, procurando minuciosamente a relação entre as estas formas e suas mediações com a realidade em uma perspectiva histórica. Só após este processo é que se pode descrever o movimento real da realidade pesquisada (MARX,1999).

Iniciamos discutindo os momentos históricos da formação docente, recorrendo a duas categorias: lócus e níveis de formação docente. Primeiro porque a concretização da política atual tem como esteio os Institutos Federais de Educação, Ciências e Tecnologia como novo lócus da formação de docentes. Segundo, porque a partir de 1996 (especificamente após a LDB n. 9.394/1996) a formação de docentes para as séries iniciais passa a ser, preferencialmente, de nível superior e retorna descaracterizada pela proposta de conjugação entre formação e avaliação profissional 


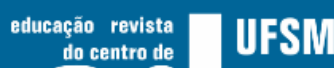 Eutiraţa}

ISSN: 1984-6444 | http://dx.doi.org/10.5902/1984644435164

pelo governo de Michel Temer (2016-2018). Neste sentido, entendemos que essas unidades de análise são importantes para compreender estes movimentos por formação que se consolidaram na atualidade.

O neoliberalismo em sua instância conceitual e estrutural requer uma constante flexibilização das instituições. Dessa feita, o lócus de formação com a prerrogativa de ensino, pesquisa e extensão não atende o interesse da ideologia neoliberal. Por outro lado, o neoliberalismo como ideologia do capital requer que a educação seja campo passível da geração do lucro. Assim, a exigência constante de maior especialização dos professores é um campo fértil para a mercantilização e, flexibilização sem a preocupação com a qualidade socialmente referenciada.

Este artigo está dividido em três partes. A primeira parte traz a um abreviado histórico da formação de professores no Brasil. A segunda discutindo o lócus nas políticas de formação docente traça um itinerário de análise mais específico do governo de Luiz Inácio Lula da Silva (2002-2011) até o governo de Michel Temer, para apresentar discussões sobre: as alternativas para melhorar a atratividade das carreiras, as propostas inovadoras para as licenciaturas e a oferta de cursos de formação continuada. Na terceira parte, desenvolve-se as conclusões visíveis a partir do conjunto das discussões.

\section{Breve Histórico}

O histórico da formação de professores no Brasil para as séries iniciais está emaranhado na história das Escolas Normais - primeiro lócus oficial e na consolidação da Pedagogia.

A preocupação com a formação dos mestres já estava presente desde o século XVII em Comenius (SAVIANI, 2009). Nossa herança de colonização europeia fez desbancar as primeiras iniciativas de formação do professor. Tanuri (2000) resgata o Alvará de 6 de novembro de 1772, que regulamentava os exames a que deviam ser submetidos os professores do ensino elementar em Portugal e nos seus domínios, mostrando que o Império, mesmo que precariamente, preocupava-se com a escolha daqueles que deveriam realizar o ensino das Letras na Coroa. 


\section{OF Eutirahá}

ISSN: 1984-6444 | http://dx.doi.org/10.5902/1984644435164

A consolidação do Estado nacional no século XIX, os ideais da Revolução Francesa levaram à criação dos sistemas públicos de ensino e o surgimento das escolas normais. No período colonial após a promulgação do Ato Adicional de 1834, que colocou sobre responsabilidade das províncias a instrução primária, surgem as primeiras Escolas Normais. Tanuri (2000) cita a do Rio de Janeiro (Niterói) em 1835, seguida da Bahia, 1836; Mato Grosso, 1842; São Paulo, 1846; Piauí, 1864; Rio Grande do Sul, 1869; Paraná e Sergipe, 1870; Espírito Santo e Rio Grande do Norte, 1873; Paraíba, 1879; Santa Catarina, 1880; Goiás, 1884; Ceará, 1885 e do Maranhão em 1890.

Saviani (2009) chama este primeiro período de Ensaios intermitentes de formação de professores (1827-1890). Tanuri (2000, p. 64) aprofunda mostrando que se depreende do currículo que se realizou nesta época o primeiro ensaio de uma instituição destinada a formação, com uma característica de ensino limitado aos estudos da escola primária, em síntese: noções de escrita e aritmética.

Os demais períodos são divididos em cinco grandes movimentos: o estabelecimento das Escolas Normais (1980-1932), a organização dos Institutos de Educação (1932-1939), a implantação dos cursos de Pedagogia e de licenciatura juntamente com a consolidação das Escolas Normais (1939-1971), a substituição da Escola Normal pela habilitação de Magistério (1971-1996) e por fim, advento dos Institutos Superiores de Educação e nas Escolas Normais Superiores e o novo perfil do Curso de Pedagogia (1996-2006) (SAVIANI, 2009).

Feito esta brevíssima retrospectiva histórica, nossa análise se deslocará para a década de 90 do século XX, momento classificado por Saviani como do Advento dos Institutos Superiores de Educação, Escolas Normais Superiores e o novo perfil do Curso de Pedagogia. Precisamos fazer este recorte temporal em função da fluidez do texto, procurando uma ligação sistêmica com o tempo e as categorias que já delimitamos na introdução.

Neste recorte, a história não é concebida pelos acontecimentos cronologicamente marcados, mas pelos elementos do passado que podem nos ajudar na compreensão do presente. Entendemos assim, que a mudança de lócus da formação de professores para os Institutos Federais de Educação, Ciências e 


\section{Althapão}

ISSN: 1984-6444 | http://dx.doi.org/10.5902/1984644435164

Tecnologia instituída pela Lei n.11.890/08 é o sétimo movimento seguindo a lógica interpretativa de Saviani (2009)2. Por isso, partimos dessa totalidade histórica que é a última década do século XX no Brasil que, mesmo sem se desfazer de todas as formas anteriores de desenvolvimento e de ideologias, começa a querer engendrar sob os auspícios da suposta democracia participativa e da social democracia à consolidação de uma nova ordem social calcada nas orientações macroeconômica do neoliberalismo.

\section{As categorias lócus e nível de formação em debate nas políticas de}

\section{formação de professores}

Na década de 1990 com a criação da Associação Nacional pela Formação dos Profissionais da Educação (ANFOPE) tem-se a volta dos debates em torno da formação. Porém, diversas bandeiras do movimento sequer foram contempladas pela Lei de Diretrizes de Bases (n. 9.394/96) mostrando o desrespeito pelo movimento de trabalhadores, pela indicação teórica sobre a formação e sobre o lócus onde está devia ser realizada.

Os embates político-ideológicos em torno da aprovação da atual Lei de Diretrizes e Bases (Lei n. 9394/96) são os orientadores de um processo que culmina com a flexibilização dos currículos, dos cursos e do tempo de formação, com a estatização e municipalização dos projetos. Além da investida dos projetos privados de formação docente. Tal perspectiva começa a se construir a partir do final dos anos 1990, reformulando os cursos de formação de profissionais da educação pela publicação dos Referenciais curriculares para a formação de professores (1999) e pelas Diretrizes Curriculares para a Formação Inicial de Professores para a Educação Básica, que junto aos pareceres do CNE n.115/99 e a Resolução CP n.04/97 evidenciam o processo de flexibilização curricular objetivando adequar os currículos aos novos perfis profissionais adequados a restruturação produtiva em curso (FREITAS, 2002).

A tessitura das políticas de formação ancoradas na legislação citada, é fruto de um conjunto de tramas políticas e da complexa reorganização produtiva que o Brasil atravessa na década de 1990. O relato de Kuenzer, à época, denuncia que a proposta 


\section{F Hsy Eutirahá}

ISSN: 1984-6444 | http://dx.doi.org/10.5902/1984644435164

apresentada por Darcy Ribeiro tinha a intenção clara de delimitar um novo espaço para a formação: Os Institutos Superiores de Educação aqueles que deviam ser a síntese das Escolas Normais e dos cursos de Pedagogia, sendo assim, uma forma de flexibilizar a formação, responsabilizar os estados pela formação e criar um lócus alternativo as universidades (KUENZER, 1998).

A Lei n.9394/96 instituiu este novo lócus de formação nos artigos 62 e 63. Ao ampliar o lócus de formação para os Institutos de Educação, a legislação abriu a possibilidade imediata da mercantilização. Essa mudança na lei se traduziu em um deslocamento do lócus da universidade para os Institutos, e na contradição de continuou aceitando como formação mínima a de nível médio e a primazia deste novo lócus.

Scheibe (2003) mostra que o artigo instaura uma desconfiguração da Pedagogia como espaço da formação de professores ao fixar dois lócus prioritários para formação: os Institutos Superiores e as Universidades no artigo 63 e, no artigo 64 da LDB, fixar os cursos de graduação em Pedagogia ou o nível de pós-graduação para os profissionais da educação para a educação básica atuarem na administração, planejamento, inspeção, supervisão e orientação educacional.

Na perspectiva da totalidade estes movimentos não ocorrem de forma isolada. A mediação proposta pela aprovação do texto da LDB (Lei n.9394/96) muda o lócus de formação e o nível, ao mesmo tempo admite que a formação continue sendo a de nível médio. Estas mudanças estão ancoradas na proposta dos organismos internacionais como o Banco Mundial, UNESCO e CEPAL e refletem o momento que a própria geopolítica mundial sofria o agravamento dos processos de globalização econômica, de reestruturação produtiva tardia do capital que inauguram o início dos processos de reforma neoliberal das instituições sociais na América Latina e no Caribe (FERREIRA, 2013).

A mudança de lócus e dos cursos, de certa forma, estabelecia mais uma significativa reforma por dentro na universidade pública brasileira, com a intenção de retirar das instituições universitárias a responsabilidade pela formação dos professores para a educação básica (SCHEIBE, 2003). Pois, além de privilegiar este novo lócus de formação, a legislação permitia a flexibilização destas instituições. $O$ 


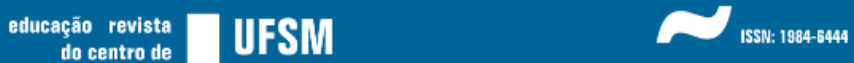 Futbab̧a}

ISSN: 1984-6444 | http://dx.doi.org/10.5902/1984644435164

art. 3ํ da Resolução CNE n. 1/99, alinhado com as recomendações dos organismos internacionais, estabelecia que os institutos superiores de educação poderiam ser organizados em:

I - como instituto superior propriamente dito, ou em faculdade, ou em faculdade integrada ou em escola superior, com direção ou coordenação do conjunto das licenciaturas ministradas;

II - como unidade de uma universidade ou centro universitário, com direção ou coordenação do conjunto das licenciaturas ministradas;

III - como coordenação única de cursos ministrados em diferentes unidades de uma mesma instituição (grifos nossos).

As possibilidades de organização deste lócus eram diversas e demonstram o desprestígio que a formação de professores tinha no projeto governamental de Fernando Henrique Cardoso (FHC) (1995-2002). Essas mudanças já se esboçavam no Ministério da Educação (MEC) desde muito cedo, pois atendiam ao projeto de flexibilização das estruturas educacionais e buscavam atender aos requisitos de flexibilidade, eficiência e produtividade nos sistemas de ensino já indicados desde o governo Itamar Franco (1992-1994) pelos organismos internacionais e por outro lado, este modelo desqualificava a profissionalização docente no país (FERREIRA, 2013).

No campo das mediações, aconteceram diversos movimentos de luta $\mathrm{e}$ resistência no interior das universidades, nos movimentos sociais organizados, destaca-se o papel da Associação Nacional pela Formação dos Profissionais da Educação, que impulsionam transformações diversas. No campo jurídico-legislativo as mudanças prosseguiriam com o Decreto n. 2.306/97, revogado em 2001 pelo Decreto $n^{0}$ 3.860/01 e, em 2006, pelo Decreto $n$. 5.773, que regulou a organização do ensino superior, a avaliação, o credenciamento e descredenciamento de cursos e instituições. O Decreto n. 5.773/06 também modificou a formação de professores, uma vez que exigiu mais eficiência científica, técnica e institucional das instituições formadoras, com o aprimoramento dos critérios de avaliação que passou exigir níveis de formação para os formadores e condições técnicos institucionais para atender estes cursos. Ao mesmo tempo, o referido decreto ratificou a diversificação de instituições de ensino superior públicas, privadas e confessionais.

Sobre a mudança de nível de formação para atuar nas séries, o Decreto $n$. 3276/99 que dispõe sobre a formação em nível superior de professores para atuar na 


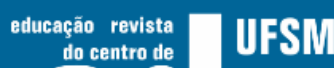 Eutirahá}

ISSN: 1984-6444 | http://dx.doi.org/10.5902/1984644435164

educação Básica, foi alterado pelo Decreto n. 3.554/00 - que retirou do curso Normal Superior a exclusividade para a formação de professores para as séries iniciais e o ensino infantil, devolvendo à Pedagogia esta responsabilidade.

Com a publicação dos Referenciais para a Formação de Professores realizada pelo MEC, temos uma nova compreensão dos caminhos que devem ser percorridos pela formação. A primeira versão deste documento se tornou pública em dezembro 1997 e, em 1998 já começaram os debates e solicitação de pareceres às instituições e pesquisadores, numa tentativa de ratificar e corporificar o documento elaborado a luz dos gabinetes do MEC. Em síntese o documento ratifica a tese da "qualificação desqualificada" dos professores, afirmando que há evidências que a formação da qual dispõe os professores tem sido insuficiente para garantir o desenvolvimento das capacidades das crianças e jovens (MEC, 2002). Exigindo dessa feita formação continuada em programas ou ações especiais para corrigir lacunas de conhecimentos relacionados a leitura e a escrita e demais conteúdos.

O documento orientou a formação para as capacidades práticas do professor como paradigma de formação. Na literatura educacional este é o momento inicial do rompimento com a racionalidade técnica presente nos projetos formativos da década de 1980, e a substituição para uma suposta "epistemologia da prática", que se caracteriza pela valorização do saber fazer do professor, calcado no tripé ação reflexão - ação.

Essas ideias se devem a dois importantes caminhos epistemológicos que ganharam espaço no Brasil, depois da publicação dos Parâmetros Curriculares Nacionais do Ensino Fundamental (1997), do Ensino Médio (2000) e do Normal Superior (2000), e dos Referencias para a formação de professores ${ }^{3}$, que é a abordagem de Competências de Philippe Perrenoud e de Professor Reflexivo de Donald Shön e outros.

Estes arranjos teóricos e metodológicos vão se inserindo no projeto de formação de professores e, reafirmando aquilo que Torriglia e Moraes (2006) defendem como tese: "uma centralidade nos docentes e uma descentralização na formação". Por sua vez, a formação está centrada nas competências, pois se pretende "subsumir os 


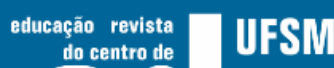 Gutraţá}

ISSN: 1984-6444 | http://dx.doi.org/10.5902/1984644435164

conhecimentos em competências, e apresentar a complexidade da prática docente em instâncias aceleradas de formação" (TORRIGLIA; MORAES, 2006, p.157).

Com a edição do Parecer CNE n. 28/01 temos uma modificação na redação do Parecer CNE 21/01, estabelecendo a duração e a carga horária dos cursos de formação de professores da educação básica. Observa-se até um papel preponderante do Conselho Nacional de Educação, definindo e normatizando a formação de professores para acompanhar as transformações trazidas pela LDB e pela edição dos decretos presidenciais que ao realizarem reformas no ensino infantil, fundamental e médio também modificam o campo da formação de professores.

$\mathrm{Na}$ continuidade deste ciclo de reformas da formação de professores no governo de $\mathrm{FHC}$, trouxeram consigo, também, parte da reestruturação universitária prevista no artigo 80 da LDB, caracterizado pelo incentivo e a regulamentação da Educação à Distância: "o Poder Público incentivará o desenvolvimento e a veiculação de programas de ensino a distância, em todos os níveis e modalidades de ensino e de educação continuada".

A educação à distância foi regulamentada, à época, pelos Decretos n. 2494/98 e 2561/98 e pela Portaria Ministerial n. 301/98. A educação à distância inaugura "novos lócus". Observamos nesta "nova forma de aprender" um caminho da fragilização do ensino superior público, modificando a formação de professores ao flexibilizar para que ela ocorra em tempos/espaços cada vez menos contundentes e sem garantia efetiva de qualidade socialmente referenciada.

Por fim, neste primeiro momento de reforma que se estende até o final dos mandatos de FHC temos uma densa legislação que ora nasce dos decretos e leis gestados no MEC ora advém da necessidade de regulação destes decretos e lei, entrando em cena o Conselho Nacional de Educação (CNE) para normatizar através de resoluções e pareceres. Essa legislação que vai se estabelecendo em torno da formação de professores, cria novos lócus de formação docente e insere novos conteúdos formativos.

Sintetizando esta fase, a formação de professores estava organizada, observando os lócus, no final do mandato de FHC como se observa na figura: 


\section{Tifus

Figura 1 - Sistema de Formação de professores de 1996-2002, com ênfase no lócus.

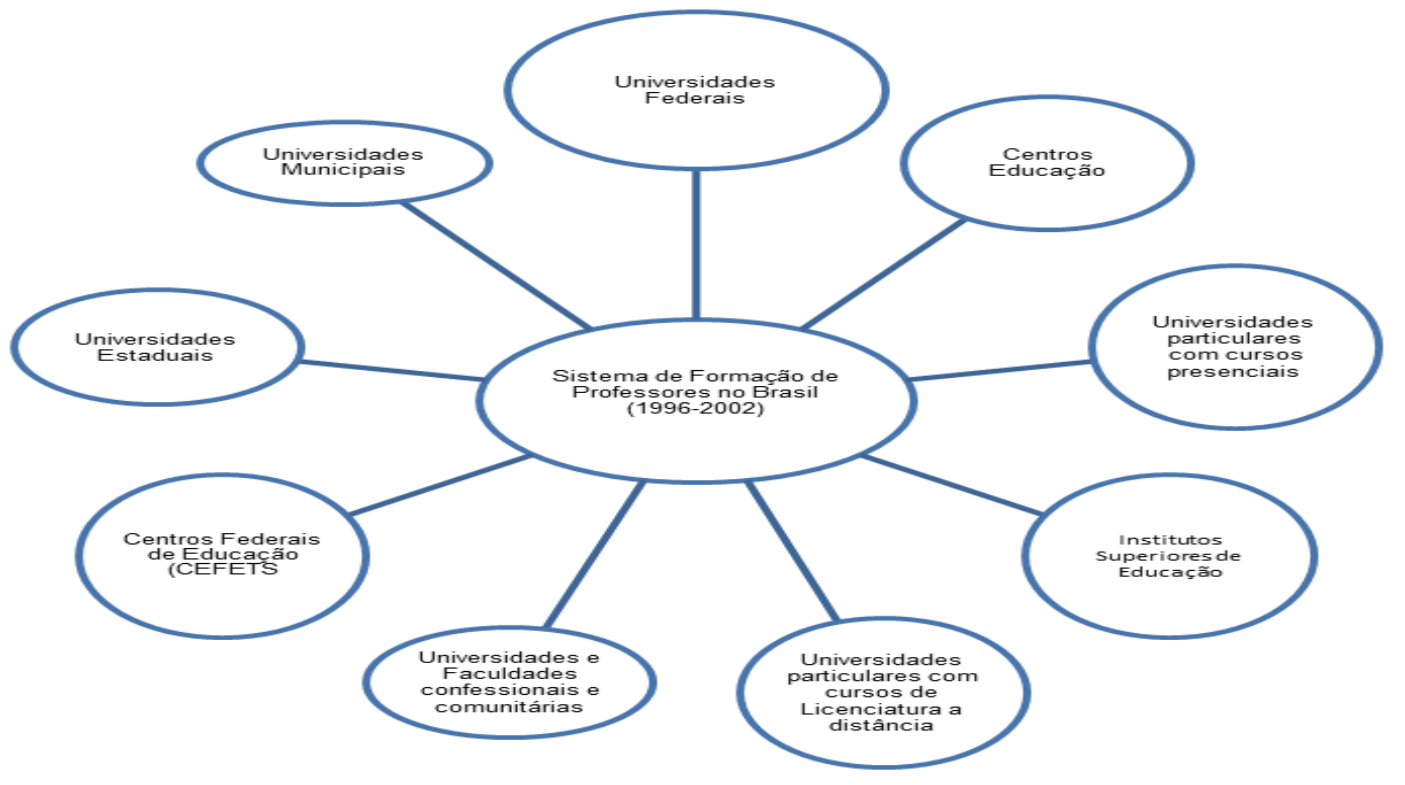

Fonte: Elaborada pelos autores

Por este motivo seja tão normal, neste momento, dos anos 1990 até 2002, perceber um cabedal de teorias que tentam direcionar a formação para um suposto corolário já testado, principalmente, em países do capitalismo avançado. No fundo, teorias como: profissionais reflexivos, epistemologia da prática, formação por competências, pedagogia dos conteúdos, objetos de ensino, matriz disciplinar (SILVA, 2009) e etc., carregam as mesmas matrizes teóricas revestidas de matizes diferentes, numa fetichização por abordagens que em grande parte procuram modificar a ação, o foco dos reais problemas da educação e não a formação e a carreira do professor.

\section{A Era Lula: A escola a distância e os novos (des) caminhos da}

\section{formação}

A segunda fase da formação se instaura no governo de Luiz Inácio Lula da Silva (2003-2011). Segunda porque observamos no final dela uma mudança significativa ao transferir o lócus para os Institutos Federais (IFs). Embora que se observe continuidades da política de formação, num quadro geral bem diferente do governo anterior, pois se tem um processo de expansão e interiorização das universidades e a criação dos IFs, não se visualiza rupturas grandiosas impostas nesta área. Porém, 


\section{工 Eutlathat}

ISSN: 1984-6444 | http://dx.doi.org/10.5902/1984644435164

a reforma empreendida pela intensa articulação legislativa no governo Lula, acaba por afetar todos os segmentos educacionais, e mesmo em um regime social democrático as reformas foram em grande parte reacionárias, assistencialistas e focais.

A tentativa do Estado foi empurrar para os entes federados a responsabilidade pela formação, o que sempre ocorreu desde o império. Para resolver o impasse da formação, uma das respostas do governo consistiu em instituir o sistema Universidade Aberta do Brasil, Decreto n. 5.800/06, o que permitiu a interiorização das vagas de ensino superior e por outro lado as de formação de professores. Uma vez que o decreto em seu capítulo primeiro estabelece como objetivo: "oferecer, prioritariamente, cursos de licenciatura e de formação inicial e continuada de professores da educação básica". Uma novidade é que se permitiu um pacto federativo mais ampliado para a formação. Pois, prefeituras e universidades pactuavam diretamente sobre a oferta de cursos e de espaços com infraestrutura para a instalação dos polos de apoio presencial.

Por outro caminho, embora tudo faça parte de um pacote só, há uma reforma da Coordenação de Aperfeiçoamento de Pessoal de Nível superior (CAPES) para atuar diretamente na formação de professores. A nova regulamentação da CAPES com a Lei n. 11.502/07 abre espaço para o regime de colaboração, com tímido financiamento desta formação e o oferecimento de bolsas para cursistas e professores formadores. A finalidade expressa foi,

[...] induzir e fomentar, inclusive em regime de colaboração com os Estados, os Municípios e o Distrito Federal e exclusivamente mediante convênios com instituições de ensino superior públicas ou privadas, a formação inicial e continuada de profissionais de magistério, respeitada a liberdade acadêmica das instituições conveniadas, observado, ainda, o seguinte: I - na formação inicial de profissionais do magistério, dar-se-á preferência ao ensino presencial, conjugado com o uso de recursos e tecnologias de educação à distância; II - na formação continuada de profissionais do magistério, utilizarse-ão, especialmente, recursos e tecnologias de educação à distância (BRASIL, 2007, grifo nosso).

A reformulação da CAPES, através da Lei n. 11.502/07, modificou as competências e a estrutura organizacional da mesma, dando-Ihe atribuições para a formação de professores para educação básica, através da reformulação dos artigos $2^{\circ}$ e $6^{\circ}$ da Lei n. 8.405/92, atribuindo a CAPES a responsabilidade de subsidiar 0 


\section{DIs: Eutirahá}

ISSN: 1984-6444 | http://dx.doi.org/10.5902/1984644435164

Ministério da Educação na formulação de políticas e no desenvolvimento de atividades de suporte à formação de profissionais de magistério para a educação básica e superior e para o desenvolvimento científico e tecnológico do País (BRASIL, 2007).

Assim, como se observa, no governo Lula a reforma estava fortemente ligada a ampliação do papel da Educação à Distância na formação de professores. Isso, se mostrará visível nas reformas do Art. 62 da LDB através da Lei n. 12.056/09 que abriu espaço para a formação usando tecnologias, dando continuidade ao caminho imposto por FHC.

Na Lei n. 12.056/09, o art. 62 da LDB passou a ter a seguinte redação: "§ $2^{\circ} \mathrm{A}$ formação continuada e a capacitação dos profissionais de magistério poderão utilizar recursos e tecnologias de educação à distância. (Incluído pela Lei n. 12.056/09). § 3º A formação inicial de profissionais de magistério dará preferência ao ensino presencial, subsidiariamente fazendo uso de recursos e tecnologias de educação à distância. (Incluído pela Lei n. 12.056/09)", não sendo obrigatória a frequência de alunos e professores (art. 47 da LDB) para atender os planos governamentais expresso no decreto de criação da Universidade Aberta do Brasil (UAB) e para normatizar uma prática comum nas instituições de ensino privadas que vinham atuando desta forma desde 1998 amparada pelos decretos n. 2494/98 e 2561/98.

Este conjunto de ações realizadas pelo governo Lula se mostram ancorados no Plano de Desenvolvimento da Educação (PDE), como grande guarda-chuva das ações a serem realizadas pelo MEC. Mas, também, como catalizador das pequenas políticas, de ações emergenciais, de mudanças normativas que permitiram criar um sistema de formação de professores diverso do governo FHC que agrega: "visão sistêmica ${ }^{4}$ da educação, territorialidade, desenvolvimento, regime de colaboração, responsabilização e mobilização social” (PDE, 2007).

Em breves linhas, a visão sistêmica do governo de Lula no PDE, coloca todo o sistema educacional como responsável pela formação de professores, ou seja, todos os entes federados deveriam pactuar com a união esta oferta de formação. A visão de colaboração está expressa no sistema UAB no Decreto n. 6.755/09 que instituiu a Política Nacional de Formação de Profissionais do Magistério da Educação Básica e 


\section{F Fs" eltoará}

ISSN: 1984-6444 | http://dx.doi.org/10.5902/1984644435164

no Plano Nacional de Formação de Professores (PARFOR). O pilar desenvolvimento e território aparecem nas políticas do governo Lula como fortes conceitos que irão perpassar quase todas as ações educativas, indo até a institucionalização dos Institutos Federais de Ciências, Educação e Tecnologia com a intenção de "promover o enlace entre educação, ordenação do território e desenvolvimento econômico e social se configura, com o PAC e o PDE, como planos de ação governamental que demandam a colaboração dos entes federados para a sua concretização" (MASSON, 2012, p.08).

No plano da responsabilização verifica-se várias ações que caminham em movimento aparentemente separados mais conjunturalmente integrados. Cabe aqui destacar a reforma da 'Nova CAPES'. Seu papel como agente regulador e agência mediadora do Estado, nos projetos de formação docente podem imprimir uma produtividade no seio da licenciatura semelhante ao que ocorre nos projetos de pósgraduação. Até aqui, os programas desenvolvidos a partir desta nova atribuição da CAPES, incorporaram marginalmente os princípios formativos requeridos pelo movimento de educadores, principalmente da ANFOPE.

A segunda fase do governo Lula para a construção de um sistema de formação de professores pode ser melhor compreendida a partir do Decreto n. 6.755/09 que instituiu a Política Nacional de Formação de Profissionais do Magistério da Educação Básica, com um caráter de disciplinar e pactuar entre os entes federados a oferta. Sobre o manto da emergência e da exceção dá-se continuidade ao projeto de formação de professores para atender a Escassez de Professores ${ }^{5}$, um dos projetos mais audacioso é o Plano Nacional de Formação de Professores (PARFOR).

As contradições dessa oferta ampliada de formação são muitas e de todas as ordens: a preocupação com a qualidade, os compromissos de pactuação entre as entidades realizadoras e os entes federados, a intensificação do trabalho nas Instituições de Ensino Superior (IES) parceiras e a insuficiência de pessoal. Todos estes problemas, típicos de programas gestados em gabinetes sem a devida atenção sobre a demanda e a qualidade da oferta, não retiram os méritos do PARFOR mas fragilizam essa política em sua ação real. Brzezinski (2012), destaca em seu relatório de acompanhamento do PARFOR que os próprios proponentes dessas políticas, os 


\section{F Hsy Eutroabat}

ISSN: 1984-6444 | http://dx.doi.org/10.5902/1984644435164

estados e os municípios não se preocupam em honrar compromissos que assegurem a permanência e a conclusão bem sucedida dos licenciandos, que há falta constante de professores e técnicos, que há o cumprimento de uma terceira jornada de trabalho pelos professores formadores e por fim, os fóruns estaduais não dispõem de um mapeamento completo dos dados da política que eles engendram.

Apesar dos diversos problemas oriundos dessa forma aligeirada e massificada de formação, que procura dar destaque somente a formação do professor como estratégia para a solução dos problemas educacionais, o gráfico 1, demonstra os resultados numéricos do PARFOR no tocante a evolução de turmas e matrículas:

\section{O (des)governo Temer: (des)lócus e (des)níveis na formação docente: Uma leitura a partir dos discursos dos intelectuais da direita}

No ano de 2015 ganham força por todo o país protestos abonados pelo slogan anticorrupção. Concomitantemente está em curso a operação Lava Jato, uma investigação para apurar indícios de corrupção e lavagem de dinheiro com recursos desviados da Petrobrás. As acusações de corrupção, o desemprego recorde e a recessão econômica, fragilizam fortemente o governo Dilma. Em tal contexto, se processou o que para alguns é entendido por golpe e para outros impedimento, que levou no ano de 2016a presidente eleita a ser retirada do poder sobre a acusação de ter realizado manipulação das contas públicas, as "pedaladas fiscais".

Com a ascensão de Temer ao governo do Brasil, dada por uma ardilosa pactuação tramada para o impeachment de Dilma Rousseff, inaugura-se uma violenta onda de ataques aos direitos coletivos dentre eles a educação.

Temos alguns reflexos claros dos efeitos do desgoverno que ferem de morte a formação dos professores já tão abalada. Dentre elas podemos destacar: o Teto de Gasto Público; a Reforma do Ensino Médio; a Reforma Trabalhista e a Reforma da Previdência que ainda está sendo tramada pelo governo ultraconservador. Essas medidas combinadas com as infinidades de benefícios e anistias que têm sido distribuídas aos poderosos em detrimento aos interesses dos pobres deste país, e no 


\section{T Hsm

ISSN: 1984-6444 | http://dx.doi.org/10.5902/1984644435164

atendimento dos mandos e desmandos dos organismos multilaterais no fortalecimento da exploração capitalista.

Dado este contexto, a reflexão sugere também a análise da proposta de nova política de formação de professores apresentada pelo Ministério da Educação (2017), dente os principais elementos propositivos destaca-se a criação de uma Base Nacional Comum da Formação de Professores da Educação Básica, dada por uma agenda que abrangeria a formação inicial e continuada. Já em 2018, foi anunciada também a proposta de alteração dos cursos de pedagogia que assumiriam a configuração formativa em que os dois primeiros anos seriam de uma base comum, o terceiro ano uma etapa de aprofundamento em educação infantil, alfabetização e anos finais e o quarto ano seria voltado para uma área de especialização, como: gestão escolar, educação profissional, didática do ensino superior e educação especial.

Tais medidas foram colocadas na pauta de discussão como se essas fossem "as medidas redentoras" para a educação brasileira, resolvendo vários gargalos. Neste sentido a formação docente se mostra altamente impactada, como veremos nas subseções a seguir, onde sintetizamos as discussões que estão postas.

\section{As propostas inovadoras para as licenciaturas}

No Brasil a evolução das matrículas nas licenciaturas tem se mostrado crescente, além dos cursos presenciais, também tem crescido o número na rede de educação à distância que conta hoje com mais de meio milhão de alunos nestes cursos. O gráfico 2 mostra o crescimento vigoroso desta oferta: 


\section{ح

ISSN: 1984-6444 | http://dx.doi.org/10.5902/1984644435164

Gráfico 2 - Evolução da matrícula em cursos de licenciatura por modalidade de ensino

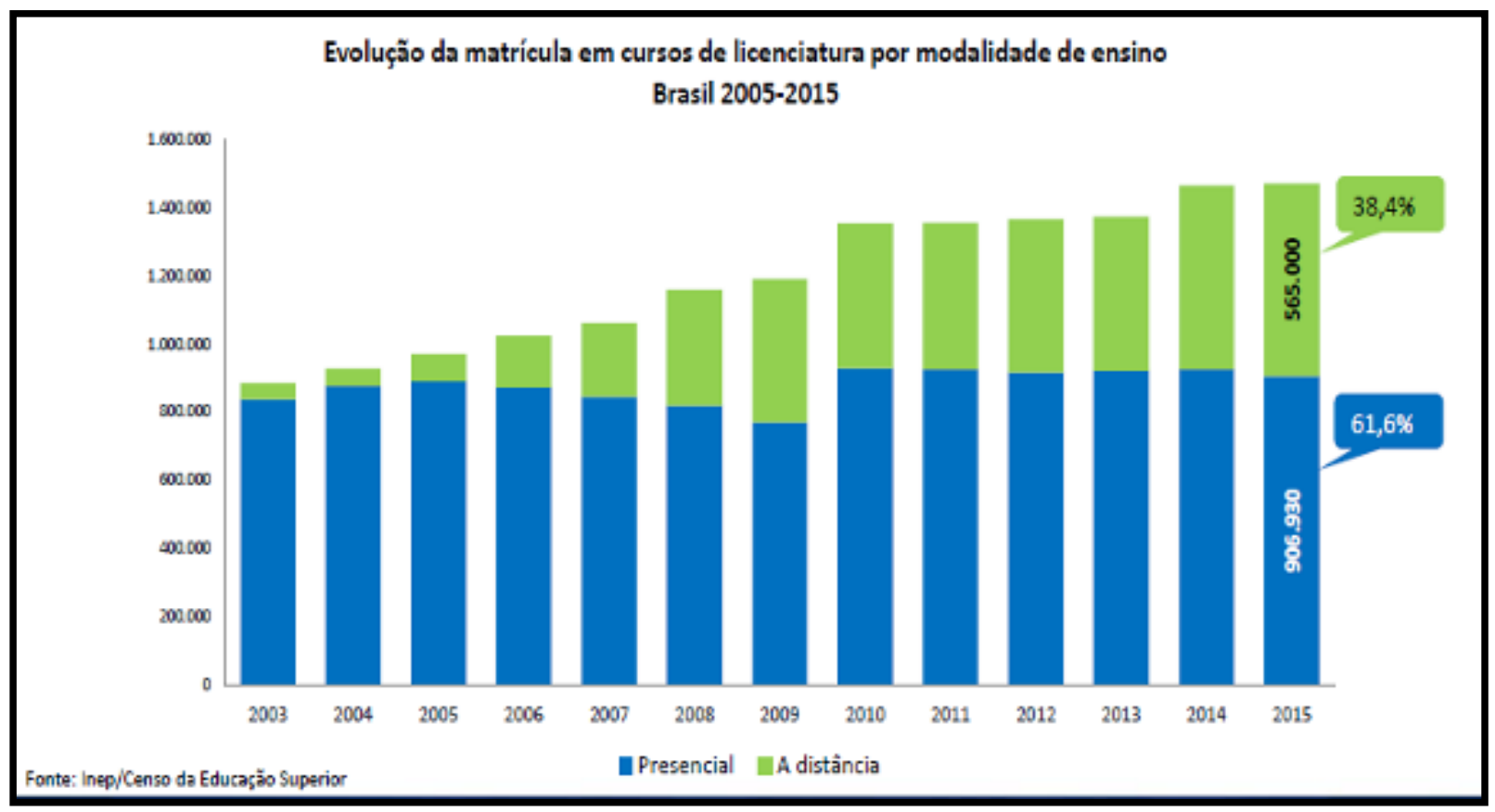

Fonte: MEC, 2017.

No Brasil 1.417.930 alunos frequentam cursos de licenciatura (MEC, 2017). Para Gatti a formação de professores nas licenciaturas mostra-se em choque direto com as demandas do trabalho para as novas gerações. Assim,

"[...] as licenciaturas se mostram em suas dinâmicas formativas alienadas das realidades socioculturais contemporâneas, da complexidade que transita do social para os espaços das escolas e das salas de aula, e das demandas que se colocam ao trabalho de um professor na interface com seus alunos no dia a dia das redes escolares" (GATTI, 2017, p. 726).

Discursos como estes que tendem a desqualificar pontualmente o trabalho sério que tem sido feito nas universidades, nos Institutos Federais e faculdades apontam para o governo a necessidade de construção de uma nova formação capaz de atender as ditas "exigências atuais de formação".

O MEC tem procurado caminho para consolidar as seguintes propostas (MEC, 2018):

I. Novos formatos para a formação inicial de professores focados no desenvolvimento de habilidades e competências profissionais com atrelamento da formação a Base Nacional Curricular Comum (BNCC) e ainda em formulação dos 


\section{FTHsy Eutrathá}

ISSN: 1984-6444 | http://dx.doi.org/10.5902/1984644435164

cursos de licenciatura com currículos flexíveis, divisão do ensino superior em ciclos, pedagogias ativas e uso intensivo de tecnologias de comunicação.

II. Criação da Residência Pedagógica.

III. O Exame Nacional de Desempenho dos Estudantes (ENADE) nas licenciaturas como mecanismo de habilitação para o exercício profissional.

IV. Formação continuada como mecanismo de evolução profissional dentro da carreira.

V. Aprovação em estágio probatório através do alcance de matriz de competências, avaliação de portfólio e avaliação de mentor.

O documento preliminar apresentado pelo MEC, além de tratar os itens elencados anteriormente, tratam inclusive da matriz de competências profissionais desejada dentro de três aspectos: conhecimento profissional, prática profissional e engajamento profissional (MEC, 2018).

A título de explicação, as residências pedagógicas como objeto da política, funcionaria inspirada no modelo de formação de médicos com a supervisão do professor formador e do professor da escola onde se daria a residência (MEC, 2018).

A residência é apresentada pelo governo como uma modernização do Programa Institucional de Bolsas de Iniciação à Docência (Pibid) e tem como objetivo principal a melhoria da qualidade da formação inicial. Para Maria Helena Castro (Secretária Executiva do MEC):

"A qualidade do professor é isoladamente o fator que mais influencia a melhoria do aprendizado. Independente das diferenças de renda e das desigualdades que existem, a qualidade do professor é o que mais pode nos ajudar a melhorar a qualidade da educação e a equidade do sistema" (VERDÉLIO, 2017).

A proposta de política, traz para a formação e para os seus sujeitos uma regime de avaliação é iniciado em seus processos de formação inicial e seria prolongado por toda carreira profissional através da "avaliação na formação". Culpabilizar o professor pelo fracasso do ensino público, na verdade pode servir para reproduzir o esfacelamento da educação em que muito provavelmente se reportará a substituição do professor formado pelo professor em formação. 


\section{T Hsm Eutirahá}

ISSN: 1984-6444 | http://dx.doi.org/10.5902/1984644435164

Torriglia e Moraes (2006) chamaram este mesmo posicionamento no governo de FHC como uma centralidade nos docentes e uma descentralização na formação. Fortalecer a formação é investir na formação dos licenciados garantindo acesso, permanência e êxito. Investir na carreira do professor, na formação dos formadores, nas instituições formativas. Mudar somente o currículo ou garantir uma espécie de "estágio para poucos" não garante as transformações culturais e sociais que se espera para efetivar a atratividade à carreira, a inserção daqueles que terminam a licenciatura nas atividades da docência.

Por outro lado, o indiscriminado favorecimento das instituições privadas como lócus de formação, assim como tem acontecido com outros programas ao longo destes últimos anos como o Programa Universidade para Todos (PROUNI), Programa Nacional de Acesso ao Ensino Técnico e Emprego (PRONATEC), pode tornar-se a "bola da vez" para a inserção do privado em programas destinados ao público. No caso em questão, a responsabilidade do Estado em formar professores para a rede de ensino seria confirmada como possibilidade das instituições particulares de ensino superior, de forma que o dinheiro público seja transferido para o setor privado para a promoção das residências pedagógicas.

Sobre o desafio de fazer convergir a formação para os objetivos da BNCC, Marchelli (2017) alerta que a ideia constituída na BNCC é que o professor só será capaz de realizar os objetivos da base se tiver uma formação inicial absolutamente diferente da praticada por cursos de licenciatura em funcionamento no Brasil.

\section{A oferta de cursos de formação continuada}

Dentre os elementos que nos causa estranheza estão o modo como se quer uniformizar um currículo de formação de professores ao desconsiderar as dimensões múltiplas em questão, quando se tem um país tão diverso como o nosso. Na mesma linha de análise do currículo, seja de formação inicial ou continuada, tem as seguintes indagações: Quem decidirá o que é a base comum? Que égide e interesses prevalecerão? As "minorias" serão espectadores ou atores? Essas e outras reflexões nos remetem ao pensamento da totalidade desconsiderada nesta imposição. 


\section{F elithahá}

ISSN: 1984-6444 | http://dx.doi.org/10.5902/1984644435164

Responsabilizar o professor pela qualidade da aprendizagem dos alunos, promover formação inicial ou continuada, sem levar em conta primeiramente a condição sócio-histórico de extrema desigualdade e exploração que estão submetidos a maioria das pessoas nesse país, chega a ser de tão agressivo, massacrante. A figura 3 ao apresentar a política, nos chama atenção para a sua dimensão formativa:

Figura 3 - Política Nacional de Formação de Professores

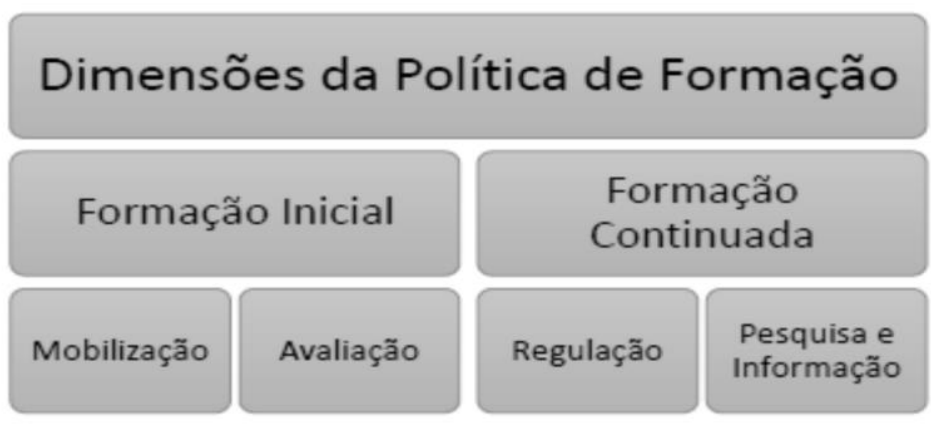

Fonte: MEC, 2017.

Damos destaque para o fator regulação, pois tal intento reproduz a condução de controle, cobrança, responsabilização muitas vezes desacompanhada das condições materiais necessárias.

Os quatro elementos defendidos pelo Ministério da Educação para a política, a saber: integração, melhorias, flexibilização do ProUni e formação continuada, nos parece tacitamente, reproduzir as políticas neoliberais que esfacelam a estrutura pública à medida que chancela os interesses hegemônico de vez, ao introduzir uma agenda de reforma educativa.

\section{Conclusões}

Nas considerações apresentadas na presente análise, destacou-se a relevância do debate das políticas de formação de professores a partir da categoria lócus de formação.

A retomada histórica da formação de professores no Brasil, serviu para acompanharmos as mudanças de lócus, num percurso que parte inicialmente das escolas normais até chegar aos Institutos Federais, como novo espaço de formação. 


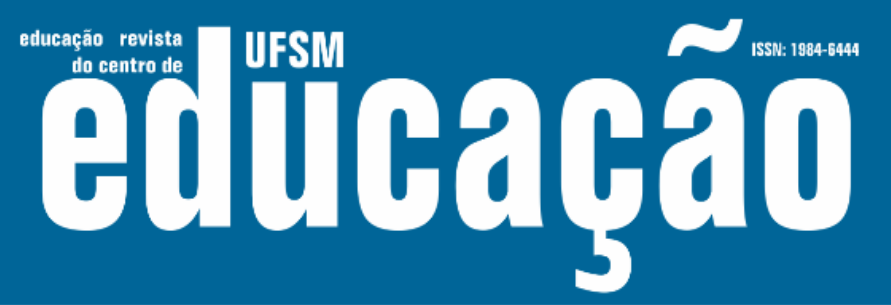

ISSN: 1984-6444 | http://dx.doi.org/10.5902/1984644435164

A crítica realizada acerca do modo como a formação de professores está sedimentada aos interesses do capital pelas ações dos governos, nos leva a diversas conclusões visíveis:

I. Qual o melhor lugar para ocorrer a formação de professores? Esta é uma das perguntas fundantes para a definição da Política de Formação. Os movimentos políticos e teóricos para formação de professores caminham sempre no espaço da instantaneidade, pelo movediço modismo teórico, sem que "as relações de trabalho e a inserção pelo trabalho terminem por determinar objetivamente a prática política [social e profissional] de cada trabalhador" (MARR, 2010, p. 335). Ou o avesso disso como formação de professores ou a inserção do professor, enquanto profissional na sociedade, transforma o seu processo concreto de sua reprodução social e direciona as formas sociais de sua práxis (MARR, 2010).

II. O lócus deixou de ser a principal discussão e há hoje, tanto na crítica quanto nas políticas governamentais uma aceitação de múltiplos espaços da formação. Porém, nossa perspectiva ainda aposta na instituição pública como lócus prioritário para a formação.

III. A formação a distância tem garantido as instituições particulares mercantilizar e flexibilizar a formação docente sem o devido cuidado com a garantia da qualidade socialmente referenciada.

IV. Por outro lado, na instância da política de formação do MEC/CAPES não temos garantia de um projeto de formação preocupado com a qualidade necessária que a formação de professores requer. Um bom indicativo são os programas de formação em serviço como o PARFOR e agora o parecer CNE/CES n. 462/2017 favorável ao mestrado e doutorado a distância precarizam ainda mais o processo.

V. Ao contrário do anunciado há uma desvalorização da profissão do professor no Brasil, tanto em termos salariais, na carreira e na responsabilização deste por "todo mal da educação brasileira".

VI. Por fim, há dificuldades no que se refere a encontrar uma proposta de formação continuada ideal que instrumentalize o professor para atuar nos anos finais do ensino fundamental e no ensino médio. E por outro lado, as reformas propostas pelo governo tornarão mais agudas as dificuldades de encontrar um consenso entre 


\section{N wism Futbabga}

ISSN: 1984-6444 | http://dx.doi.org/10.5902/1984644435164

a crítica e a política sobre o que é necessário para a formação de professores no Brasil.

\section{Notas}

1 Fazemos referências aos PL-7180/2014, PL 867/2015, PL 193/2016 e a PEC 241/2016 (Aprovada na Câmara dos Deputados) que tramitam nas casas legislativas brasileiras.

2 Essa é a interpretação de Aquino e Otranto (2004) no artigo: A formação de professores nos Institutos Federais de Educação: velhos caminhos ou novas possibilidades?

3 Projeto de Estruturação do Curso Normal Superior orientado pelo PARECER CNE № 970/99 - CES - Aprovado em 9.11.99.

4 A União ampliou suas funções de controle de qualidade, avaliação e definições de padrões curriculares. Isso possibilitou, através da avaliação de larga escala, definições de padrões curriculares que cada sistema local deve imprimir as suas ações educativas. Hoje, a educação básica brasileira conta com 26 sistemas estaduais, um distrital e 5.561 sistemas municipais cada um com autonomia (parcial) para legislar.

5 Relatório produzido pela Comissão Especial instituída para estudar medidas que visem a superar o déficit docente no Ensino Médio (CNE/CEB), composta por Antonio lbañez Ruiz, Mozart Neves Ramos, Murílio Hingel.

6 Programas e projetos da CAPES/MEC de formação do professor: Sistema UAB - seis (Profmat) de 2010; o Profletras e o ProFis em 2013; e os ProfArtes, Filosofia, ProfiAP e ProfHistória. Além de formação de professores de Línguas em países da Europa e nos Estados Unidos, ações do programa Ciências sem Fronteiras e as Olimpíadas de Física, Astronomia, Língua Portuguesa, Matemática e História em escala nacional.

\section{Referências}

ARAUJO, José Júlio César do N. A precarização da formação de professores para a educação básica no Instituto Federal de Ciência, Educação e Tecnologia do Acre - Campus Cruzeiro do Sul.Tese (Doutorado em Educação) - Faculdade de Educação, Universidade de Federal do Amazonas. Manaus, p. 261. 2018.

AQUINO, Iná Jana Souza de; OTRANTO, Célia Regina. A formação de professores nos Institutos Federais de Educação: velhos caminhos ou novas possibilidades? ANAIS DO XXII SEMINÁRIO NACIONAL UNIVERSITAS/Br. Natal, 2014. Disponível em:

www.universitas.ce.ufrn.br/ANAIS_DO_XXII_SEMINARIO_NACIONAL_UNIVERSIT AS.pdf. Acesso em: 22 mar 2018.

BRASIL. Decreto n. 5.786, de 24 de maio de 2006. Dispõe sobre os centros universitários e dá outras providencias. Disponível em: http://www.planalto.gov.br. Acesso em: 10 fev. 2018. 
ISSN: 1984-6444 | http://dx.doi.org/10.5902/1984644435164

BRASIL. Lei n. 11. 892, de 29 de dezembro de 2008. Institui a Rede Federal de Educação Profissional, Científica e Tecnológica, cria os Institutos Federais de Educação, Ciência e Tecnologia, e dá outras providências. BRASIL, 2008a. Disponível em: http://www.planalto.gov.br/ccivil_03/_ato2007-2010/2008/lei/l11892.htm. Acesso em: 29 set. 2017.

BRASIL. Lei n. 11.502, de 11 de julho de 2007. Modifica as competências e a estrutura organizacional da fundação Coordenação de Aperfeiçoamento de Pessoal de Nível Superior - CAPES. BRASIL, 2007. Disponível em: http://www.planalto.gov.br/ccivil_03/_ato2007-2010/2007/Lei/L11502.htm. Acesso em: 4 jan. 2017.

BRASIL. Lei n. 12.056, de 13 de outubro de 2009. Acrescenta parágrafos ao art. 62 da Lei no 9.394, de 20 de dezembro de 1996, que estabelece as diretrizes e bases da educação nacional. Disponível em: http://www.planalto.gov.br/ccivil_03/_ato20072010/2009/lei/l12056.htm. Acesso em: 29 set. 2017.

BRASIL. Lei n. 9.394, de 20 de dezembro de 1996. Fixa as Diretrizes e Bases da Educação Nacional. Disponível em: http://www.planalto.gov.br/Ccivil_03/leis/L9394.htm Acesso em: 10 de jan. 2018.

BRASIL. MEC vai oferecer $80 \mathrm{mil}$ vagas de residência pedagógica em 2018.Disponível em: http://agenciabrasil.ebc.com.br/educacao/noticia/2017-10/mecvai-oferecer-80-mil-vagas-de-residencia-pedagogica-em-2018. Acesso em: 02 nov. 2017.

BRASIL.Parecer CNE/CES n. 970/99, de 09 de Novembro de 1999. Curso Normal Superior e da Habilitação para Magistério em Educação Infantil e Séries Iniciais do Ensino Fundamental nos cursos de Pedagogia. Disponível em: http://www.scielo.br/pdf/es/v20n68/a17v2068.pdf. Acesso em: 10 de jan. 2018.

BRZEZINSKI, Iria. Observatório da formação e valorização docente: configurações e impactos da implementação dos Fóruns Permanentes de Apoio à Formação do Magistério. Relatório Técnico Final elaborado por Iria Brzezinski, coordenadora da pesquisa financiada pelo CNPq Processo n. 481941/2010-0, desenvolvida no período de novembro/2010 a dezembro/2012. Goiânia, 2012. Disponível em http://www.gppege.org.br/home/secao.asp?id_secao=267\&id_unidade=1. Acesso 12 de dez. de 2015.

CAPES. Plano Nacional de Formação de Professores da Educação Básica PARFOR PRESENCIAL: Manual operativo. Brasília: CAPES, 2013. Disponível em: http://www.capes.gov.br/images/stories/download/legislacao/ManualOperativoPARF OR-mar13.pdf. Acesso em: 17 mar. 2019. 


\section{Aitloab̧ão}

ISSN: 1984-6444 | http://dx.doi.org/10.5902/1984644435164

FERREIRA, Adriano de Melo. A inovação nas políticas educacionais no Brasil: Universidade e formação de professores. Tese de doutorado em Educação, UFG, 2013.

FREITAS, Helena Costa Lopes de. Formação de professores no Brasil: 10 anos de embate entre projetos de formação. Educ. Soc., Campinas, vol. 23, n. 80, setembro/2002, p. 136-167. Disponível em: www.cedes.unicamp.br. Acesso em: 21 mar. 2018.

GARCIA, Carlos Marcelo. A Formação de professores: para uma mudança educativa. Portugal: Porto Editora, 1999.

GATTI, Bernardete Angelina. Formação de professores, complexidade e trabalho docente. Rev. Diálogo Educ., Curitiba, v. 17, n. 53, p. 721-737, 2017. Disponível em: https://periodicos.pucpr.br/index.php/dialogoeducacional/article/viewFile/8429/17739 . Acesso em: 22 mar. 2018.

KUENZER, AcaciaZeneida. A formação de educadores no contexto das mudanças no mundo do trabalho: Novos desafios para as faculdades de educação. Educ. Soc. [online]. 1998, vol.19, n.63, pp.105-125. http://dx.doi.org/10.1590/S010173301998000200007 .

LIMA, Telma Cristiane S; MIOTO, Regina Celia T. Procedimentos metodológicos na construção do conhecimento científico: a pesquisa bibliográfica. Rev. Katál. Florianópolis v. 10 n. esp. p. 37-45, 2007.

MARCHELLI, Paulo Sergio. Base nacional comum curricular e formação de professores: o foco na organização interdisciplinar do ensino e aprendizagem. Revista de estudos de cultura, n.7, jan/abr. 2017. Disponível em: https://seer.ufs.br/index.php/revec/article/view/6555/5385. Acesso em: 22 mar. 2018.

MARR, Wolfgang Leo. Política como práxis: Hegemonia às avessas, um exercício teórico. In: OLIVEIRA, Francisco de; BRAGA, Ruy; RIZEK, Cibele (orgs.) Hegemonia ás avessas: economia, política e cultura na era da servidão financeira. São Paulo: Boitempo, 2010.

MASSON, Gisele. Implicações do plano de desenvolvimento da educação para a formação de professores. Ensaio: aval. pol. públ. Educ., Rio de Janeiro, v. 20, n. 74, p. 165-184, jan./mar. 2012.

MEC. Projeto de Estruturação do Curso Normal Superior. Brasília: MEC, 2000. Disponível em: http://portal.mec.gov.br/cne/arquivos/pdf/projcns.pdf. Acesso em:10 fev. 2018. 
MEC. Proposta para Base Nacional Comum da Formação de Professores da Educação Básica: Versão preliminar. Brasília: MEC, 2018. Disponível em: http://portal.mec.gov.br/index.php?option=com_docman\&view=download\&alias=1050 91-bnc-formacao-de-professores-v0\&category_slug=dezembro-2018pdf\&ltemid=30192. Acesso em: 17 mar. 2019.

MEC. Referenciais para a Formação de Professores. Brasília: MEC, 2002. Disponível em: http://www.dominiopublico.gov.br/download/texto/me000511.pdf. Acesso em: 10 fev. 2018.

PEREIRA, Maria de Fátima R.; PEIXOTO, Elza Margarida de M. A distância: a escola Lula para a formação de professores. Revista HISTEDBR On-line, Campinas, n.40, p. 179-188, dez.2010 - ISSN: 1676-2584.

RUIZ, Antoniolbanez; RAMOS, Mozart Neves; HINGEL, Murílio. Relatório - Escassez de professores no ensino médio: soluções emergenciais e estruturais. Brasília: MEC, 2007. Disponível em: http://portal.mec.gov.br/cne/arquivos/pdf/escassez1.pdf. Acesso em: 22 mar. 2018.

SAVIANI, Demerval. Formação de professores: aspectos históricos e teóricos do problema no contexto brasileiro. Revista Brasileira de Educação, Rio de Janeiro, v. $14 \quad$ n. $40 \quad$ jan./abr. $2009 . \quad$ Disponível em http://www.scielo.br/pdf/rbedu/v14n40/v14n40a12.pdf. Acesso 10.05.2014.

SCHEIBE, Leda. Formação de professores e pedagogos na perspectiva da LDB. In: BARBOSA, Raquel Lazzari Leite (org.) Formação de educadores: desafios e perspectivas. São Paulo: Editora UNESP, 2003.

SILVA, M. Complexidade da formação de professores: saberes teóricos e saberes práticos [online]. São Paulo: Editora UNESP; São Paulo: Cultura Acadêmica, 2009. 114 p. ISBN 978-85-98605-97-5. AvailablefromSciELOBooks.

TANURI, Leonor Maria. História da formação de professores. Revista Brasileira de Educação, n. 14, p. 61-88, maio/ago. 2000.

TAVARES, Moacir Gubert. A Constituição e a implantação dos Institutos Federais no contexto da educação superior no Brasil: O Caso do IFC - Câmpus Rio do Sul. Tese de doutorado. Ponta Grossa: Universidade Estadual de Ponta Grossa, 2014.

TORRIGLIA, Patricia Laura. A formação docente no contexto histórico político das reformas educacionais no Brasil e na Argentina. Tese de Doutorado em Educação. Universidade Federal de Santa Catarina, Florianópolis, 2004. 


\section{$7=1 \mathrm{~s}$

ISSN: 1984-6444 | http://dx.doi.org/10.5902/1984644435164

TORRIGLIA, Patricia Laura; MORAES, M. C. M. Brasil e Argentina: uma compreensão histórica-política da formação docente. Cuadernos de Educación (Córdoba), v. 4, p. 139-151, 2006.

VERDÉLIO, Andreia. MEC vai oferecer 80 mil vagas de residência pedagógica em 2018.Brasília: Agencia Brasil, 2017. Disponível em: http://agenciabrasil.ebc.com.br/educacao/noticia/2017-10/mec-vai-oferecer-80-milvagas-de-residencia-pedagogica-em-2018. Acesso em: 17 mar. 2019.

\section{Correspondência}

José Júlio César do Nascimento Araújo - Professor doutor do Instituto Federal do Acre Campus Cruzeiro do Sul.

Marcondes de Lima Nicácio - Professor doutor do Instituto Federal do Acre - Campus Cruzeiro do Sul.

Instituto Federal de Educação, Ciência e Tecnologia do Acre - Campus de Cruzeiro do Sul. Estrada da APADEQ, no 1.192, Ramal da Fazenda Modelo, Bairro Nova Olinda. CEP 69.980-000, Cruzeiro do Sul, Acre, Brasil.

E-mail: jose.araujo@ifac.edu.br - marcondesnicacio@gmail.com

ORCID iD: https://orcid.org/0000-0003-1045-3284 - https://orcid.org/0000-00019463-2815

\section{c) (i) (8)}

This work is licensed under a Creative Commons Attribution-NonCommercial 4.0 International (CC BY-NC 4.0) 